\title{
Tribute to Pierre D. Delmas
}

\author{
R. D. Chapurlat
}

(C) International Osteoporosis Foundation and National Osteoporosis Foundation 2009

I first met Pierre Delmas in 1989, when I was a young medical student during a rotation in the division of endocrinology of Edouard Herriot Hospital. He had given a talk while establishing a collaborative project on thyroid and bone with his endocrinologist colleagues. I did not know then that he would later be my teacher and mentor in rheumatology, but I was already impressed by the clear mind, the vision, the rigor, the charisma.

Indeed, he was among the few academics with the ability to combine clinical skills, research work and teaching with equal achievement. But what was most striking was his ability to allow his collaborators to work with great autonomy, yet ensure everything was still supervised rigorously. Everyone's creativity was stimulated, but also wisely guided. All of us in the group believe that preserving and developing his tremendous intellectual heritage is what he desired. Today, this is possible because he taught us to work independently, his way. This issue of Osteoporosis International is very important to us, because, a year after he left us, we are proud to show with three scientific articles that his legacy is still alive. His lab is working well, we have already achieved important goals and have many projects running. The cohorts will continue, a new one will be recruited soon, and the bone quality research field is expanding.

From the clinics to the bench, and from the bench to the clinics was also his creed. Here too, he succeeded so well that, when I see his former patients, they always express deep regret and gratitude. This tribute from patients is certainly the most important point among the many things the bone community has said and written over the past year.

R. D. Chapurlat $(\bowtie)$

Division of Rheumatology, INSERM Research Unit 831,

National Reference Centre for Fibrous Dysplasia of Bone,

Hôpital E. Herriot,

69437 Lyon, France

e-mail: roland.chapurlat@laposte.net 